\title{
Measuring the effect of innovations in teaching methods on the performance of accounting students
}

Citation for published version (APA):

Bollen, L. H. H., Janssen, J. B. P. E. C., \& Gijselaers, W. H. (2000). Measuring the effect of innovations in teaching methods on the performance of accounting students. METEOR, Maastricht University School of Business and Economics. METEOR Research Memorandum No. 040 https://doi.org/10.26481/umamet.2000040

Document status and date:

Published: 01/01/2000

DOI:

10.26481/umamet.2000040

Document Version:

Publisher's PDF, also known as Version of record

\section{Please check the document version of this publication:}

- A submitted manuscript is the version of the article upon submission and before peer-review. There can be important differences between the submitted version and the official published version of record.

People interested in the research are advised to contact the author for the final version of the publication, or visit the DOI to the publisher's website.

- The final author version and the galley proof are versions of the publication after peer review.

- The final published version features the final layout of the paper including the volume, issue and page numbers.

Link to publication

\footnotetext{
General rights rights.

- You may freely distribute the URL identifying the publication in the public portal. please follow below link for the End User Agreement:

www.umlib.nl/taverne-license

Take down policy

If you believe that this document breaches copyright please contact us at:

repository@maastrichtuniversity.nl

providing details and we will investigate your claim.
}

Copyright and moral rights for the publications made accessible in the public portal are retained by the authors and/or other copyright owners and it is a condition of accessing publications that users recognise and abide by the legal requirements associated with these

- Users may download and print one copy of any publication from the public portal for the purpose of private study or research.

- You may not further distribute the material or use it for any profit-making activity or commercial gain

If the publication is distributed under the terms of Article $25 \mathrm{fa}$ of the Dutch Copyright Act, indicated by the "Taverne" license above, 


\title{
Measuring the effect of innovations in teaching methods on the performance of accounting students
} An empirical study into the relationship between learning objectives, teaching methods,
knowledge levels and the performance of students in an accounting context.

\author{
Laury Bollen \\ Department of Accounting and Auditing \\ Faculty of Economics and Business Administration \\ Maastricht University \\ Boudewijn Janssen \\ Department of Accounting and Auditing \\ Faculty of Economics and Business Administration \\ Maastricht University \\ Wim Gijselaers \\ Department of Educational Development and Research \\ Faculty of Economics and Business Administration \\ Maastricht University
}

Maastricht Accounting and Auditing Research and Education Center (MARC)

Faculty of Economics and Business Administration

Universiteit Maastricht

MARC Working Paper M AR C-W P/3/2000-02

Correspondence to L.Bollen@BERFIN.unimaas.nl 


\section{Introduction}

Research on teaching methods that are employed in courses in abstract subject area's such as mathematics, physics and also accounting, shows that traditional methods of instructing and evaluating students still predominate to a large extent, based on teaching and evaluation methods such as lectures and multiple choice exams ${ }^{1}$. However, there are also examples of instructors or institutions that have either revised individual courses or have redesigned their entire curriculum to modernise and improve the educational process $^{2}$. Teachers that are engaged in improving the educational process by looking for new and innovative ways to design their courses or organise their curriculum, inherently face the problem of measuring the impact of such changes. Usually, the effect of course revisions is measured by using student evaluations or changes in exam results. The primary argument of this research paper is that such instruments may provide an inadequate basis for evaluating the impact of educational changes on student performance. This premise was based on the experiences taken from the revision of an intermediate accounting course for business economics students. In the course discussed in this paper, for a number of years the passing rate for the closing written exam had been a problem as less than $50 \%$ of the students passed the course exam, indicating that the applied eaching methods did not adequately prepare them to meet the course objectives. However, the annual student evaluations of this course revealed that the quality of this structure was rated satisfactory and students typically complained on minor practical elements of the course that should be improved. These mixed signals eventually resulted in a project involving teaching staff, students and educationalists in which the structure of the course was re-evaluated through re-examining the learning objectives and the instructional design of the course. New learning objectives were specifically aimed at teaching students cognitive strategies to apply existing knowledge on accounting procedures in a new (unfamiliar) setting. From the objectives defined, a new instruxtional design was developed explicitly aimed at meeting the course objectives. Given the inconsistent results of the student survey and the exam results, a research project was undertaken to asses the consequences of the changes in educational methods that were adopted.

\footnotetext{
${ }^{1}$ for an overview of teaching methods used in accounting curricula of US institutions see Dow and Feldmann (1997)

${ }^{2}$ for accounting related examples see f.e. Stout and Mohanan [1998], Kirch and Cavalho [1998] and Porter and Carr [1999]
} 
The aim of this paper therefore is to demonstrate the effectiveness of a change in teaching methods, that was based on an explicit restructuring of learning objectives, in the context of an intermediate accounting course. In doing so, the paper discusses the measurement of educational innovations that aim at attaining specifically defined learning goals, particularly the ability of students to acquire meta-knowledge and procedural knowledge instead of declarative knowledge. Secondly, the paper addresses the ongoing debate on the need for changes in both the content of and teaching methods used in accounting courses, in order to better prepare accounting students for the requirements of business practices. The empirical part of the paper focuses on the effects of teaching methods on the performance of students, using specifically designed research instruments instead of student surveys or exam results. It aims to examine in various ways whether the innovations in accounting education succeeded in realising the course objectives differentiating between various knowledge levels.

\section{Motivation for curriculum change}

Abstract, model-oriented academic courses deviate from other types courses to the extent in which the courses' participants have to rely on abstract models - in contrast to for instance reproductive knowledge. In terms of the taxonomy of Anderson (1990), such courses place a high emphasis on the ability of students to acquire meta-knowledge and procedural knowledge, instead of declarative knowledge. Intermediate bookkeeping courses are examples of such abstract courses, where students are required to obtain insight in the (high order) rules of accounting problems. In many cases, courses on fundamental accounting procedures (such as bookkeeping) are treated as a skills training, were student are required to reproduce accounting procedures in a (semi-) familiar setting. As a result of this approach, students acquire little insight into the general structure of accounting procedures and they lack the ability to apply the skills they have been taught, in unfamiliar settings, which they will encounter in practice. Therefore, courses on accounting procedures should aim at providing students with strategies to apply existing knowledge on accounting procedures and concepts (acquired in first level accounting courses) in settings that they have not been faced with before. In this respect, accounting educators face 
problems that are also documented in other educational fields such as physics (see fe. Chi et al. [1981]) and mathematics (see Bonner and Walker [1994]).

Bonner [1999] argues that specifying learning objectives ${ }^{3}$ should be the first step in the process of choosing appropriate teaching methods. In general three types of learning objectives may be distinghuised: verbal information, intellectual skills and cognitive strategies (Gagné, 1984). Verbal information is at the lower end of the scale and refers to the factual content of a particular area of knowledge. Given this type of objective, students are expected to reproduce factual knowledge presented to them, for example in the form of a definition. In this setting, students should be presented with factual information in an organised way, where the instructor facilitates the reproduction of knowledge by relating the teaching material to examples, explanations or related topics so that students can develop various ways to recall the information.

Intellectual skills involve various skills that all relate to the application of knowledge to novel situations. Such skills can vary from classification skills, where students are able to recognise particular instances to more general concepts (e.g. recognise a transaction as being a revenue or expense), to more advanced skills, where students are required to generate new rules by combining old rules (for example generate a journal entry for an accelerated depreciation method from existing knowledge on linear depreciation). In this context, instructors should present and facilitate the recollection of factual knowledge and rules. They should also facilitate the application of these rules to novel situations, by providing multiple examples from which students can generalise their knowledge and develop a framework from which they can apply their knowledge in an new - but not entirely unfamiliar - context.

The highest level of learning objectives involves the development of cognitive strategies by students. Given this objective, students are required to develop an effective as well as efficient strategy to solve an unfamiliar problem situation. For example students may be familiarised with accounting procedures for leasing contracts and provided with examples that relate to various types of leasing settings (for example operational lease and financial lease contracts). The

\footnotetext{
3 A learning objective can be defined as a formal description of the projected outcome of the educational process.
} 
learning goal would then be that students are confronted with a setting in which there is no reference to leasing, but in which the generic elements of a leasing contract are embedded. As a consequence, they should be able to recognise this problem as one that can be effectively and efficiently solved by applying the accounting procedures for leasing, which may have to be adapted slightly to fit the particular situation presented in the example. In order to achieve this type of learning objective instructors should add to their teaching a description, demonstration and examples of appropriate strategies to deal with unfamiliar settings. A new element here is that the answer a students produces when faced with an unfamiliar setting should not only be evaluated based on its effectiveness (i.e. characterised as correct or incorrect) but must also be evaluated in terms of efficiency (i.e. quality of the problem solving process).

\section{Course redesign}

The intermediate accounting course under scope of study is the second in a series of three courses. The first course in this sequence is an introductory accounting course in the first year, which is a mandatory course for all economics and business students (approximately 1000 students per year). This course is followed up in the second year by the intermediate accounting course, which is mandatory for all business economics students (approximately 300 students per year). During the third year, business economics students can choose to enrol in the advanced accounting course (approximately 100 students per year).

The introductory accounting course mainly stresses the fundamental accounting definitions and principles and applications and thus focuses on declarative knowledge. In this course students are familiarised with the accounting cycle, with the basic structure of an accounting system and with accounting principles. The intermediate course builds on the material covered in the introductory course, especially with regard to cost allocation systems and procedures for preparing consolidated accounts. Until the academic year 1998/1999 the general format of the course consisted of a weekly plenary lecture (about 150 students) and a weekly medium size group meeting (40 to 60 students per group) during which the current week's assignments were discussed. All meetings lasted approximately two hours. In the assignments, students had to apply the accounting procedures introduced to them in the plenary session and further explained 
in the textbooks, to new situations they had not encountered before, but which had similar characteristics as the smaller examples used in the lectures and textbooks. The course was concluded by a three hour written exam that consisted of two open ended questions that were similar to the assignments used during the course.

From the annual evaluation of the course by students combined with the results of the final exam of the course, the following notable aspects were discerned:

- passing grades for the course (both for the initial final exam as well as for the resit) tended to be on the low side, compared with other second year courses;

- the students found the course difficult, especially as a result of a lack of coherence between the literature used and the assignments students had to prepare.

Based on these findings the course was restructured completely in 1999. The approach of the restructuring process was very similar to the approach suggested by Bonner [1999] based on the explicit definition of learning goals for the course, followed by a restructuring of teaching methods ${ }^{4}$. As a result, the learning goal of the course was explicitly aimed at procedural knowledge (e.g. higher-order rules and cognitive strategies) as opposed to the declarative knowledge that was taught in the introductory accounting course. Among others, the following underlying problems with the structure of the current course were reported:

- for some students (dependent on prior education) there seemed to be a mismatch between their previous knowledge (i.e. declarative knowledge) and the knowledge required to engage successfully in the intermediate course;

- students attained insufficient knowledge about the general concepts of accounting procedures taught during the course (higher order rules);

\footnotetext{
4 The restructuring of the course as described here, occurred before the publication of Bonner's article. However, the approach that was used was almost identical as the approach suggested by Bonner. This approach mostly results from the fact that the course described is part of a curriculum that is based on Problem Based Learning (PBL). In a PBL-structure, teachers constantly have to define which learning goals students are expected to derive from every task that is part of a course. Although the intermediate accounting course is not a PBL-course in itself, the PBL environment in which it operates resulted in an approach that focussed on the definition of learning goals to organise the restructuring of the course.
} 
- transfer of knowledge was insufficiently applied to new problem areas (cognitive strategies), which however was required to successfully pass the final written exam.

As a result student motivation was low which had an inverse effect on student performance (that is: the low motivation partly refrained students from participating in and studying for the course).

As a result of this analysis, the following changes were incorporated in the course for the academic year 1999/2000:

1. one plenary lecture and one small group meeting of about 15 students was held each week;

2. the small group meeting consisted of presentations and discussions of assignment that were prepared in advance by small groups of 3 to 4 students;

3. the written solutions to the assignments had to be handed in each week;

4. a partial grade for presentations and handed-in solutions was applied to the final grade for the course;

5. project assignments were included that combine several different accounting concepts within one single assignment;

6. a six-step approach was introduced, guiding the students through the process of analysing and solving new situations when making the assignments.

The first four elements were intended to increase the motivation of students by providing a combination of teaching methods (plenary lectures, assignments prepared in small groups, presentations by students) and adequate feedback mechanisms (both from fellow students and staff). This structure should allow for the activation of the relevant prior knowledge (declarative knowledge) and the transfer of knowledge on basic concepts and rules ((low level intellectual skills). The two final elements were newly developed. Project assignments were included to stress the high order rules used. The projects combined the theory from several weeks into one single case in order to stress similarities (and differences) between the various subjects taught in the course. The six-step approach was included to facilitate the development of cognitive strategies by students. This approach structures the process of analysing an unfamiliar problem 
situation and aims at finding and applying an efficient and effective strategy to solve the underlying accounting problem presented in that situation ${ }^{5}$.

\section{Assesment of the effects of the course redesign}

\section{RESEARCH INSTRUMENTS}

To test whether the changes that were implemented in the course resulted in better performance of the students with regard to the learning goals that were set, specific test instruments were developed to test the progress of the participating students in several areas ${ }^{6}$. The research instrument used in our study is based on research conducted by Chi (1981) and her co-workers. Chi et al. showed that students with insufficient knowledge in a particular domain tend to organize their representation around the surface structure of the problems. Knowledge of these students is organized around literal objects explicitly given in a problem statement. This is in sharp contrast with experts' knowledge. This knowledge is organized around principles and abstractions that subsume these objects. It is generally assumed that the relation between the structure of the knowledge base and problem-solving process is mediated through the quality of the representation of the problem. For example, physics experts represent physics problems in abstract terms like point-masses or massless strings, whereas novices often use naive concepts, such as blocks, ropes and slopes. These naive concepts are often direct observations based on common sense, resulting in misconceptions about physics.

\footnotetext{
5 The six steps are: (1) describe the content of the problem, (2) analyse the financial facts, (3) specify the information needs relevant to the problem, (4) analyse the structure of the statement of accounts (general ledger), (5) prepare the joumal entries, (6) evaluate whether the predefined information needs are met.

${ }^{6}$ The full research study included three instruments submitted to the students:

1. A motivation/prior knowledge questionnaire. The goal of this questionnaire was to relate the students' motivation to their course achievement. It also provides information on the prior knowledge of the students.

2. A categorization assignment to test the conceptual knowledge of students (high order intellectual skills);

3. A case analysis to investigate the abilities of students to transfer knowledge to new domain areas (cognitive strategy).

The current paper, however, only reports the results that are based on the categorization assignment.
} 
The study conducted by Chi, et al. (1981) is a case in point. These researchers focused on the initial encoding of problems to account for expert novice differences. They asked experts and novices to sort a large number of problems into categories of similar problems. It was assumed that experts' encoding would incorporate information about solution methods. They found that categories of problems reflected the principles underlying the problems, whereas the novices' categories were based on the situations and objects mentioned in the problem text.

The present study followed a similar methodology as developed by Chi et al. Each problem contained two or three cues, however, only one of these was really relevant as an accounting problem. All cues included in the descriptions were examples of one of four categories of general concepts that make up the accounting course ${ }^{7}$.

The objective of this study was to determine the kinds of categories that subjects with different experience levels impose on problems. A procedure was used to categorize 16 problems, that were designed at the level at which students should have arrived by the end of the accounting course. Instructions were to write down the problem-numbers, and give a description of the underlying (accounting) problem, thus grouping cases with similar underlying problems.

\section{RESEARCH SAMPLE}

For this research design two groups of participants were selected. The first group consisted of students who participated in the intermediate accounting course in the academic year 1999/2000. This group was split-up in three subgroups, students with high, medium or low achievements. The subgroup classification was based on the score for the introductory accounting course with a sensitivity check on the score for the parallel first-year course (which covered accounting and finance topics).

The second group consisted of students who did not pass the course in the previous year and were therefore repeat students. This group is interesting as a control group since these students have originally been trained in the 'old' teaching structure of the course. These students typically do not follow the course as intensively as regular students since they have already followed this

\footnotetext{
${ }^{7}$ The four categories of general concepts that underlie the case-problems are cost allocation methods, obligo entries, methods of valuation for fixed assets and the preparation of consolidated accounts.
} 
course in a previous year. Due to the smaller size of this group, it was not split up into subgroups.

Descriptive statistics for all sample groups are provided in table 1.

Table 1. Sample descriptives

\begin{tabular}{lcccc}
\hline & N (students) & \% male students & Years of study & $\begin{array}{c}\text { Average grade } \\
\text { for first year } \\
\text { course }\end{array}$ \\
\hline Economics-Low & 8 & 62.5 & 1 & 4.8 \\
Economics-Medium & 18 & 55.6 & 1 & 6.2 \\
Economics-High & 12 & 50 & 1 & 8.3 \\
\hline Economics-Total & 38 & 55.26 & 2.6 & 5.55 \\
\hline Repeat students & 15 & 33.3 & & 5.0 \\
\hline Total sample & 53 & & 1 & \\
\hline
\end{tabular}

\section{Results}

The most common technique to test the performance of students at the end of a course is to have them take a written exam. The results of a written exam should provide an overall indication of the performance of students on various aspects that are taught in a course, both at the level of procedural and declarative knowledge. For the accounting course under study in the paper, the results for the written exam are presented in figure 1 below. The results show that the performance of the various subgroups of students tends to converge, in the sense that the difference between low-level students and high level students as defined at the beginning of the course tends to decrease. To a large extent this effect is a result of the measuring instrument used. The classification at the beginning of the course is based on the level of declarative knowledge of students (as measured by their grade for the first year introductory accounting course). The intermediate course, however, was based on learning goals that focused on procedural knowledge and consequently the written test at the end of this course therefore measures both declarative and procedural knowledge. Any change in performance that is based on the written exam for both courses, therefore represents a combination of changes in declarative knowledge as well as

\footnotetext{
${ }^{8}$ All grades are recalculated on a 0 to $100 \%$ scale.
} 
changes in procedural knowledge ${ }^{9}$. Consequently, the results of the written exam provide little insight in the extent to which the learning objectives related to procedural knowledge have been achieved. Therefore, the categorization technique used in our research is intended to provide a more detailed insight in the performance of students, as it takes into account the level of knowledge involved in the task that is performed by the student.

Figure 1. Results of the final exam.

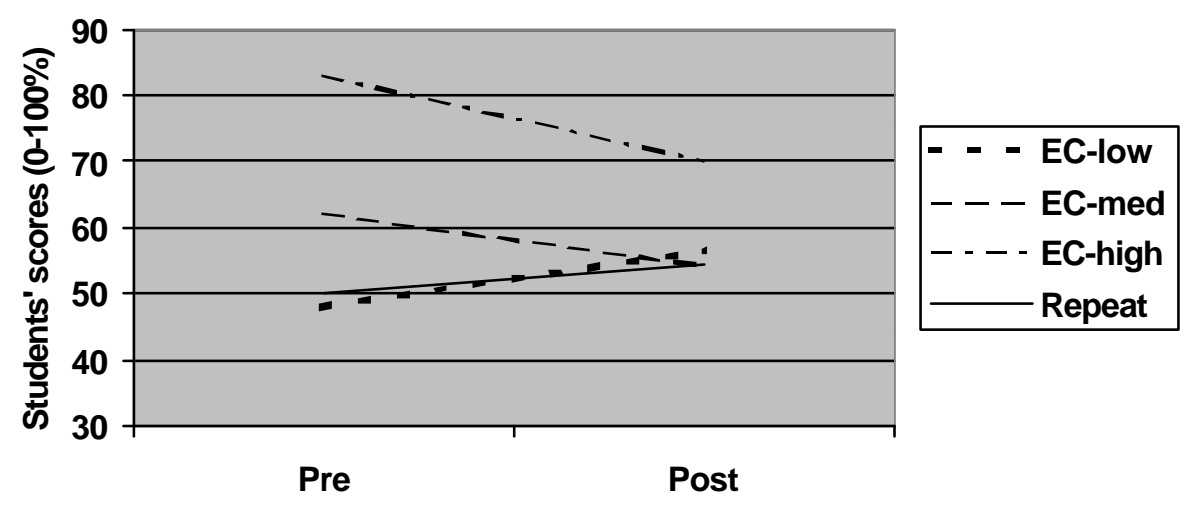

In the categorization analysis, students were asked to categorize sixteen case descriptions. Each case entailed references to at least two different accounting problems. In each case, however, only one of the accounting problems related to an actual underlying accounting problem. All accounting problems mentioned in the cases related to one of the four general categories covered in the accounting course. The case descriptions were evenly divided among the four general categories. Students were asked to indicate to what accounting problem each of the case descriptions was related. Students were allowed to mention more than one accounting problem per case. Students were asked to take this categorization test at the beginning and at the end of the course (which was seven weeks later). In both instances the same case descriptions were used.

\footnotetext{
${ }^{9}$ This may also explain why the performance of high-level and medium-level seems to degrade. For these students declarative knowledge was already relatively high at the beginning of the course, so in this respect they can gain relatively little extra in a course were the focus is more on procedural knowledge and doesn't add a whole lot on declarative knowledge. Low-level students however still can gain a lot on declarative knowledge even in a course that merely reuses the declarative knowledge that was already taught in the introductory course.
} 
The analysis of the results of the categorization technique involves a number of steps. The first part of the analysis focuses on the descriptions subjects gave for the accounting problem that was the subject of each of the case descriptions. For this analysis all accounting problems mentioned by students were related to one of the four general categories covered in the accounting course. Accounting problems mentioned that could not be related to one of the four categories were classified as incorrect, all other were classified as correct. This procedure was done independently by two of the researchers. Differences in opinion were discussed by the research team and were classified subsequently.

Three different measures on the performance of the students were used:

\begin{tabular}{|l|l|}
\hline Measure & Description \\
\hline LLIS1: Total number of concepts mentioned & $\begin{array}{l}\text { Measures the degree to which the case descriptions is } \\
\text { recognised as relevant in an accounting context. }\end{array}$ \\
\hline LLIS2: Number of correct concepts mentioned & $\begin{array}{l}\text { This measure indicates the degree to which the subjects } \\
\text { recognise the case descriptions as an accounting problem } \\
\text { that is relevant in the context of the subjects covered in } \\
\text { the course. }\end{array}$ \\
\hline LLIS3: Relative number of correct concepts mentioned & $\begin{array}{l}\text { This measure indicates the degree to which the subjects } \\
\text { recognise the case descriptions as an accounting problem } \\
\text { that is relevant in the context of the subjects covered in } \\
\text { the course, relative to the degree to which the problem is } \\
\text { recognised as relevant in an accounting context. }\end{array}$ \\
\hline
\end{tabular}

With respect to the level of learning objectives, these measures indicate low-level intellectual skills (LLIS), particularly the identification of concepts. All three measures are expected to have improved at the end of the course, for all groups of students. The detailed results for each of these measures is presented in the tables 1a through $1 \mathrm{c}$ in the appendix. The main results are summarised in the table below. 
Table 2. Performance on low-level intellectual skills

\begin{tabular}{|c|c|c|c|c|c|c|}
\hline & \multicolumn{2}{|c|}{ LLIST } & \multicolumn{2}{|c|}{ LLIS2 } & \multicolumn{2}{|c|}{ LLIS3 } \\
\hline & Pre & Post ${ }^{2,3}$ & Pre & Post $^{2,3}$ & Pre & Post ${ }^{2,3}$ \\
\hline Ecs-Low & 7.25 & $8.50^{* * \pi}$ & 5.00 & $7.75^{\star \star \pi *}$ & 0.69 & $0.91^{* * \pi}$ \\
\hline Ecs-Medium & 5.66 & $8.83^{* * *}$ & 4.44 & $7.88^{\approx \pi *}$ & 0.79 & $0.90^{* * *}$ \\
\hline Ecs-High & 7.25 & $8.33^{*}$ & 5.66 & $8.16^{\text {*** }}$ & 0.80 & $0.97^{* \pi *}$ \\
\hline Ecs-1otal & 6.50 & $8.06^{* \times 1}$ & 4.94 & $7.94^{\times \pi \times}$ & 0.77 & $0.93^{* \times \pi}$ \\
\hline $\begin{array}{l}\text { Repeat } \\
\text { students }\end{array}$ & 6.53 & $8.06^{\pi \times}$ & 4.93 & $6.80^{* \pi}$ & 0.79 & 0.85 \\
\hline Total sample & 6.38 & $7.92^{\pi x}$ & 4.91 & $7.41^{\pi \times \pi}$ & 0.77 & $0.89^{\approx \pi}$ \\
\hline
\end{tabular}

For all dimensions higher scores correspond to better categorization efforts.

${ }^{2}$ Test performed: $T$-test for 2 related samples

${ }^{3}$ Significance levels indicated as ${ }^{* *}$ for $\alpha<=0.01 .{ }^{* *}$ for $\alpha<=0.05$ and * for $\alpha<=0.1$

The results for the all three measures used indicate that the performance for the total group of students has increased significantly by the end of the course. For the total sample of students, this result holds for each of the four general categories covered in the course.

For all three measures used in this part of the analysis, economics students perform better compared to repeat students, but the difference between both groups is not significant. Also, within the group of economics students, no significant differences occur between low-level, medium-level and high-level students, although high-level students generally do show the highest scores on all measures. In the pre-test, repeat students show results that are comparable to the medium-level economics students. In the post test, repeat students perform lower than all economics subgroups, while the knowledge levels of these latter groups seem to converge to the same level (see figure 2).

A detailed analysis per subgroup of students (see tables $1 \mathrm{~b}$ and $1 \mathrm{c}$ in the appendix) shows that the improvement of performance is not constant over the four general categories that are covered in the course. For the first category (cost allocation), both LLIS2 and LLIS3 are considerably higher compared to all other categories. Also, LLIS3 shows a decrease for this first category, whereas all other categories show an increase. LLIS3 is a relative measure that relates the number of topics mentioned for one general category to the total number of concepts mentioned for all general categories combined. Apparently, the increase in topics mentioned for the last three categories is relatively higher. As a result the total number of topics mentioned for all four categories 
combined increases more strongly than the number of topics relating to the first category, resulting in a decrease of relative frequently for this particular category. For the other three categories the opposite effect can be found, indicating that the increase in performance for these categories is relatively larger. This result indicates that students show larger increases for the three categories for which they show lower levels of declarative knowledge at the start of the course. Also, the increase in declarative knowledge is consistent for these three categories, independent of their position in time within the course.

Figure 2. Results for LLIS2

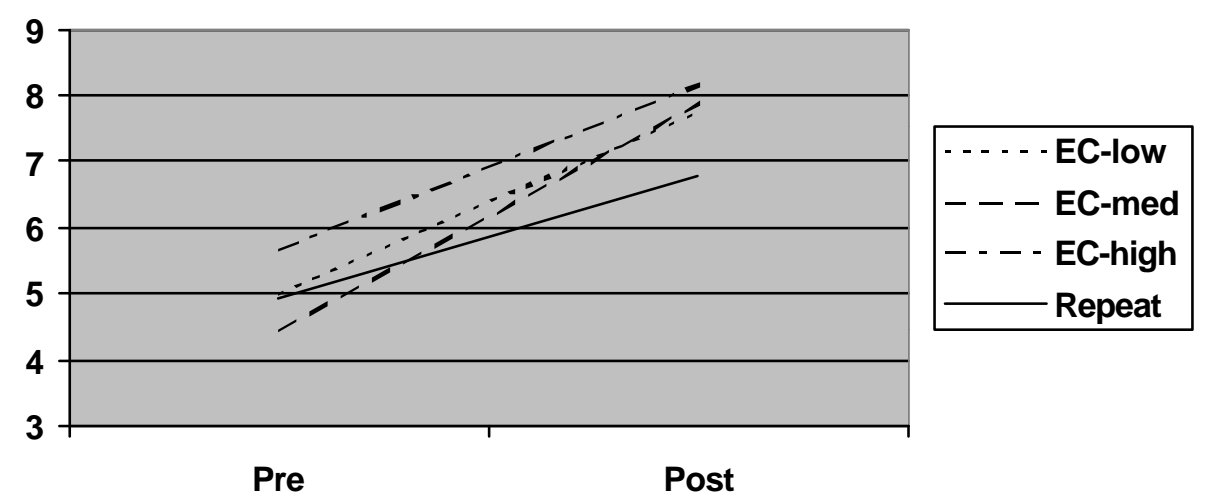

The second part of the analysis of the categorization study focussed on the way the case descriptions were related to the underlying accounting concepts. The analysis uses the structure of the cases as each case description is a combination of at least two accounting problems of which one is the primary accounting problem. Secondly, the analysis uses the fact that the case descriptions partly share the underlying accounting problems in the sense that they all relate to one of the four categories dealt with in the course. The analysis focuses on the ability of students to recognise and correctly combine the multiple accounting problems within the 16 case descriptions. For this part of the analysis, again three different measures for the performance of students were used: 


\begin{tabular}{|l|l|}
\hline Measure & Description \\
\hline HLIS1: Recognition effort & Number of accounting problems recognised \\
\hline HLIS2: Recognition quality & Number of accounting problems correctly recognised \\
\hline HLIS3: Classification quality & $\begin{array}{l}\text { Number of cases correctly classified within the relevant } \\
\text { general accounting category }\end{array}$ \\
\hline
\end{tabular}

The measures used in this second part of the categorization analysis indicate high-level intellectual skills (HLIS), particularly the application of learned rules and concepts to a new situation. The measures indicate to which extent students recognise and combine the underlying accounting problems in the case descriptions. The first measure indicates to what extent students recognise multiple accounting concepts within case descriptions. The second measure indicates to what extent students correctly recognise the underlying accounting problems and the degree to which these are shared by multiple case descriptions. The final measure indicates to what extent students recognise the primary accounting problem that underlies each case description and thereby measures to what degree students correctly combine cases that share the same primary problem. The detailed results for each of these measures is presented in the tables $2 \mathrm{a}$ through $2 \mathrm{c}$ in the appendix. A summary of these results is presented in table 3 below.

Table 3. Performance on high-level intellectual skills

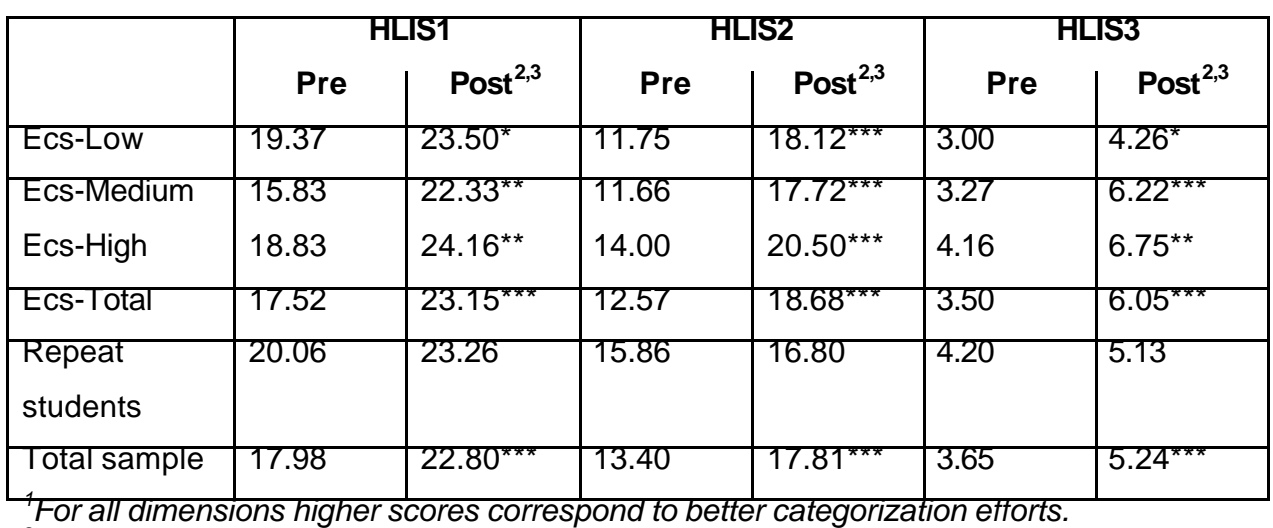

${ }^{2}$ Test performed: $T$-test for 2 related samples

${ }^{3}$ Significance levels indicated as ${ }^{* *}$ for $\alpha<=0.01$. ** for $\alpha<=0.05$ and * for $\alpha<=0.1$

The results of the analysis show that for the first measure, indicating the total number of accounting problems mentioned for the combined case descriptions, the performance for the 
economics students increases significantly, whereas there is only a minor increase in the performance of the repeat students. In the pre-test repeat students perform better than the economics students, and at the end of the course the level of both groups is virtually the same and the repeat students have lost their advantage. Nevertheless, the increase in performance during the course for economics students is not significantly higher compared to the repeat students. Within the group of economics students, no significant differences between subgroups can be found.

For the measure on the recognition quality (i.e. the number of correct accounting problems recognised) a similar result can be observed: In the pre-test repeat students outperform the economics students but at the end of the course economics students outperform the repeat students. In this case the increase in performance during the course for economics students is significantly higher compared to the repeat students. Within the group of economics students, for this measure, the group of high-economics students performs better than the other groups of economics students, but these differences are not significant.

Figure 4. Results for HLIS3

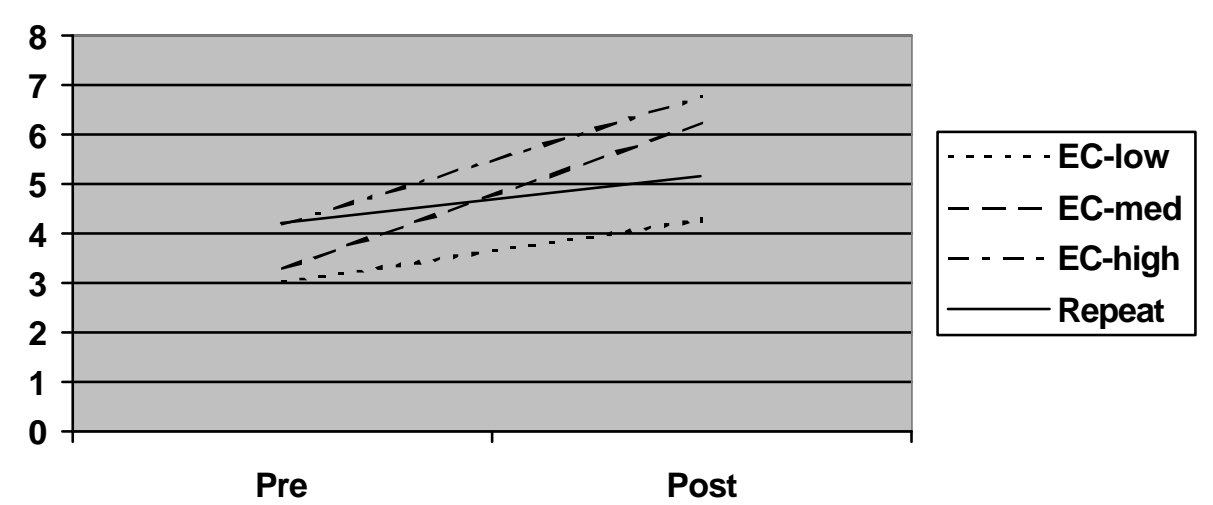

For the third measure, at the start of the course economics and repeat students generally show the same scores. At the end of the course economics students have significantly improved their performance while repeat students only show a minor improvement. Within the economics students, there are no significant differences between the three subgroups. Although high-level economics students show slightly better performance levels both at the start and at the end of the 
course, the improvement in performance during the course generally is the largest for mediumlevel students (see figure 4).

\section{Conclusions}

This paper discusses the results of an empirical study on the effects of a set of teaching methods employed in an intermediate accounting course, that aim at achieving learning goals oriented towards the improvement of procedural knowledge (i.e. high order intellectual skills and cognitive strategies). The study uses a categorization technique in order to attest whether procedural knowledge has increased as a result of the teaching methods employed.

Firstly, an analysis of exam results shows that the performance of the various subgroups of students tends to converge, in the sense that the difference between low-level students and high level students as defined at the beginning of the course tends to decrease. This finding may be explained by the fact that any change in performance that is based on the written exam represents a combination of changes in declarative knowledge as well as changes in procedural knowledge. These results seem to indicate that final exam results may provide an insufficient basis for evaluating the performance of students on specific knowledge levels. Consequently, to measure the effect of educational innovations that aim for specific learning goals, specific instruments should be used whereas student surveys and exam results provide only limited insight in the success of such innovations.

The results of the study show that the set of teaching methods employed in the accounting course under study, does improve both declarative and procedural knowledge. With respect to the level of declarative knowledge, low level students seem to catch-up with high-level and medium level students during the course. Since the course is aimed at improving procedural knowledge, medium- and high-level students have relatively little opportunity to further improve their declarative knowledge. With respect to procedural knowledge all subgroups of students improve their level and high-level students attain a higher end-level compared to low-level students. Furthermore the results show that economics students do not outperform repeat students. With 
respect to procedural knowledge, significant differences exist between economics students and the control group.

A high level of declarative knowledge is not sufficient for gaining an advantage on the level of procedural knowledge. With respect to the level of improvement during the course, no significant differences between subgroups can be found, indicating that high-level students cannot outperform low-level students with respect to procedural knowledge, although they succeeded in outperforming them in a previous course that focused on teaching declarative knowledge.

The improvement of procedural knowledge depends on time. For topics that are dealt with later in the course, students show larger improvements in procedural knowledge indicating it takes them time to adjust. For declarative knowledge the improvement during the course is not dependent on time.

The categorization technique used in this study focuses on the performance of students with respect to high level intellectual skills. In a further study, the effect of the teaching methods employed in the intermediate accounting course on cognitive strategies will be explored. This study should provide further insights into the degree to which specific sets of teaching methods can be employed to achieve learning goals that aim at enhancing various elements of procedural knowledge. Also, motivational aspects will be further investigated to assess the relationship between changes in knowledge levels and motivation dimensions such as the cognitive competence of students, their affection with accounting subjects, the perceived difficulty of the subjects covered in accounting courses and the perceived usefulness and relevance of the subject of the course. 


\section{References}

- Anderson, J.R., Cognitive Psychology and its Implications, 3rd edition, New York, NY: Freeman, 1990

- Bonner, Sarah E., A Model of the Effects of Audit Task Complexity, Accounting, Organizations and Society, Vol. 19, No. 3, 1994

- Bonner, Sarah E., Choosing Teaching Methods Based on Learning Objectives: An Integrative Framework, Issues in Accounting Education, Vol. 14, No. 1, February 1999

- Bonner, Sarah E. and Paul L. Walker, The Effects of Instruction and Experience on the Acquisition of Auditing Knowledge, The Accounting Review, Vol. 69, No. 1, January 1994

- Chang, C. Jamie, Joanne L.Y. Ho and Woody M. Liao, The effects of justification, task complexity and experience/training on problem/solving performance, Behavioral Research in Accounting, volume 9, supplement 7, 1997

- Chi, M. T. H., Feltovitch, P. J., \& Glaser, R Categorization and representation of physics problems by experts and novices. Cognitive Science, 5, 1981

- Dow, Kathy J. and Dorothy A Feldmann, current approaches to teaching intermediate accounting, Issues in Accounting Education, vol. 12, no. 1, spring 1997

- Gagné, R.M., Learning outcomes and their effects: Useful categories of human performance, American Psychologist, April 1984

- Gal, J. and J.B. Garfield, The assessment challenge in statistics education, Amsterdam: IOS Press, 1997

- Giacomino, Don E. and Michael D. Akers, An examination of the differences between personal values and value types of female and male accounting and nonaccounting majors, Issues in Accounting Education, vol. 13, no. 3, august 1998

- Herz, Paul J. and Joseph J Schultz jr, the role of procedural and declarative knowledge in performing accounting tasks, Behavioral Research in Accounting, volume 11, 1999

- Hill, Mary Callahan, Class size and student performance introductory accounting courses: further evidence, Issues in Accounting Education, vol. 13, no. 1, february 1998

- Keef, Stephen P. and Melvin L. Roush: New Zealand Evidence in the Performance of Accounting Students: Race, Gender and Self-concept, Issues in Accounting Education, Vol.12, No. 2, Fall 1997

- Kirch, David, and Gerard Cavalho, The delivery of accounting in the problem-based learning environment, in: Milter, Richard, John Stinson and Wim Gijselaers, Educational Innovation in Economics and Business, volume 3, Kluwer Academic Publishers, Dordrecht, 1998

- Libby, Robbert, The role of knowledge and memory in audit judgement, in: Judgement and decision making research in accounting and auditing, ed. R.H. Ashton \& A.H. Ashton, Cambridge University Press, New York, 1993/1995.

- Libby, Robbert and Hun-Tong Tan, Modeling the Determinants of Audit Expertise, Accounting, Organizations and Society, Vol. 19, No. 8, 1994

- Libby, Robbert and Joan Luft, Determinants of Judgment Performance in Accounting Settings: Ability, Knowledge, Motivation and Environment, Vol. 18, No. 5, 1993

- Philips, Fred, Accounting Students' Belief About Knowledge: Associating Performance with Underlying Belief Dimensions, Issues in Accounting Education, Vol.13 No.1, February 1998

- Porter, Brenda, and Shirley Carr, From strategic plan to practical realities: developing and implementing a zero-based accounting curriculum, Issues in Accounting Education, volume 14, no. 4, 1999 
- Stout, David and Thomas Monahan, Longitudinal Assesment of Case-Based Teaching in the Required Undergraduate Cost Accounting Course, in: Milter, Richard, John Stinson and Wim Gijselaers, Educational Innovation in Economics and Business, volume 3, Kluwer Academic Publishers, Dordrecht, 1998 
Appendices 
Table 1a. Results of categorization analysis based on number of concepts mentioned (LLIS1)

\begin{tabular}{|l|c|c|c|}
\hline & Pre & Post & Test $^{2,3}$ \\
\hline Ecs-Low & 7.25 & 8.50 & $3.416^{\star \star *}$ \\
\hline Ecs-Medium & 5.66 & 8.83 & $3.633^{\star \star *}$ \\
\hline Ecs-High & 7.25 & 8.33 & $1.900^{\star}$ \\
\hline Ecs-Total & 6.50 & 8.06 & $4.402^{\star \star *}$ \\
\hline Repeat students & 6.53 & 8.06 & $2.182^{\star *}$ \\
\hline Total sample & 6.38 & 7.92 & $4.652^{\star \star *}$ \\
\hline
\end{tabular}

${ }^{1}$ For all dimensions higher scores correspond to better categorization efforts.

${ }^{2}$ Test performed: T-test for 2 related samples, $t$ scores are reported

${ }^{3}$ Significance levels indicated as ${ }^{* *}$ for $\alpha<=0.01$. ${ }^{* *}$ for $\alpha<=0.05$ and * for $\alpha<=0.1$ 
Table 1b. Results of categorization analysis: number of correct concepts mentioned (LLIS2)

\begin{tabular}{|c|c|c|c|c|c|c|c|c|c|c|c|c|c|c|c|}
\hline & \multicolumn{3}{|c|}{$\begin{array}{c}\text { Category } 1 \\
\text { Cost allocation }\end{array}$} & \multicolumn{3}{|c|}{$\begin{array}{c}\text { Category } 2 \\
\text { Obligo entries }\end{array}$} & \multicolumn{3}{|c|}{$\begin{array}{c}\text { Category } 3 \\
\text { Valuation of assets }\end{array}$} & \multicolumn{3}{|c|}{$\begin{array}{c}\text { Category } 4 \\
\text { Consolidation }\end{array}$} & \multicolumn{3}{|c|}{ Categorization - total } \\
\hline Sample & Pre & Post & Test $^{2,3}$ & Pre & Post & Test $^{2,3}$ & Pre & Post & Test $^{2,3}$ & Pre & Post & Test $^{2,3}$ & Pre & Post & Test $^{2,3}$ \\
\hline Ecs-Low & 3.12 & 3.25 & 0.424 & 0.50 & 1.87 & $2.582^{* *}$ & 0.87 & 1.37 & 1.871 & 0.50 & 1.25 & $2.393^{\star \star}$ & 5.00 & 7.75 & $4.919^{\star \star \star}$ \\
\hline Ecs-Med & 2.77 & 3.61 & $2.051^{*}$ & 0.27 & 1.55 & $5.657^{* * \star}$ & 0.69 & 1.08 & $2.176^{\star \star}$ & 0.69 & 1.63 & $4.074^{\star \star \star}$ & 4.44 & 7.88 & $5.632^{* \star \star}$ \\
\hline Ecs-High & 3.12 & 3.12 & 0.000 & 0.54 & 1.95 & $4.691^{* \star *}$ & 1.12 & 1.70 & $1.984^{*}$ & 0.87 & 1.37 & 1.625 & 5.66 & 8.16 & $4.282^{\star \star \star}$ \\
\hline Ecs-Total & 2.96 & 3.38 & $1.613^{* * *}$ & 0.41 & 1.34 & $7.582^{* \star *}$ & 0.86 & 1.34 & $3.519^{\star \star \star}$ & 0.71 & 1.47 & $4.778^{\star * *}$ & 4.94 & 7.94 & $8.293^{\star \star \star}$ \\
\hline $\begin{array}{l}\text { Repeat } \\
\text { students }\end{array}$ & 2.53 & 2.73 & 0.544 & 0.80 & 1.93 & $2.747^{* \star}$ & 0.86 & 0.93 & 0.299 & 0.73 & 1.20 & $2.226^{\star *}$ & 4.93 & 6.80 & $2.256^{* \star}$ \\
\hline $\begin{array}{l}\text { Total } \\
\text { sample }\end{array}$ & 2.80 & 3.13 & $1.561^{\star \star *}$ & 0.50 & 1.75 & $7.553^{\star \star *}$ & 0.87 & 1.21 & $3.057^{* \star *}$ & 0.72 & 1.36 & $4.943^{\star \star *}$ & 4.91 & 7.41 & $7.136^{\star \star \star}$ \\
\hline
\end{tabular}

${ }^{1}$ For all dimensions higher scores correspond to better categorization efforts.

${ }^{2}$ Test performed: T-test for 2 related samples, $t$ scores are reported

${ }^{3}$ Significance levels indicated as ${ }^{* \star *}$ for $\alpha<=0.01 .{ }^{* *}$ for $\alpha<=0.05$ and ${ }^{*}$ for $\alpha<=0.1$ 
Table 1c. Results of categorization analysis: relative number of correct concepts mentioned (LLIS3)

\begin{tabular}{|c|c|c|c|c|c|c|c|c|c|c|c|c|c|c|c|}
\hline & \multicolumn{3}{|c|}{$\begin{array}{c}\text { Category } 1 \\
\text { Cost allocation }\end{array}$} & \multicolumn{3}{|c|}{$\begin{array}{c}\text { Category } 2 \\
\text { Obligo entries }\end{array}$} & \multicolumn{3}{|c|}{$\begin{array}{c}\text { Category } 3 \\
\text { Valuation of assets }\end{array}$} & \multicolumn{3}{|c|}{$\begin{array}{c}\text { Category } 4 \\
\text { Consolidation }\end{array}$} & \multicolumn{3}{|c|}{ Categorization - total } \\
\hline Sample & Pre & Post & Test $^{2,3}$ & Pre & Post & Test $^{2,3}$ & Pre & Post & Test $^{2,3}$ & Pre & Post & Test $^{2,3}$ & Pre & Post & Test $^{2,3}$ \\
\hline Ecs-Low & 0.56 & 0.40 & $2.751^{\star \star}$ & 0.12 & 0.23 & 1.572 & 0.18 & 0.18 & 0.122 & 0.11 & 0.18 & 1.131 & 0.69 & 0.91 & $4.258^{\star \star \star}$ \\
\hline Ecs-Med & 0.61 & 0.44 & $4.604^{* \star *}$ & 0.06 & 0.19 & $3.979^{\star * \star}$ & 0.17 & 0.14 & 0.633 & 0.14 & 0.20 & 1.543 & 0.79 & 0.90 & $2.897^{* \star *}$ \\
\hline Ecs-High & 0.56 & 0.37 & $2.832^{\star \star}$ & 0.08 & 0.23 & $3.072^{\star \star}$ & 0.19 & 0.20 & 0.315 & 0.15 & 0.17 & 0.512 & 0.80 & 0.97 & $3.396^{* * *}$ \\
\hline Ecs-Total & 0.59 & 0.41 & $5.951^{* * *}$ & 0.08 & 0.21 & $5.195^{\star * *}$ & 0.18 & 0.17 & 0.375 & 0.14 & 0.19 & $1.902^{*}$ & 0.77 & 0.93 & $5.720^{\star * *}$ \\
\hline $\begin{array}{l}\text { Repeat } \\
\text { students }\end{array}$ & 0.50 & 0.41 & $1.905^{\star}$ & 0.16 & 0.26 & $2.692^{* \star}$ & 0.17 & 0.12 & 1.622 & 0.14 & 0.19 & 1.460 & 0.79 & 0.85 & 1.127 \\
\hline $\begin{array}{l}\text { Total } \\
\text { sample }\end{array}$ & 0.56 & 0.41 & $5.954^{\star * \star}$ & 0.10 & 0.23 & $5.956^{\star \star \star}$ & 0.18 & 0.16 & 0.837 & 0.14 & 0.18 & $1.985^{*}$ & 0.77 & 0.89 & $4.802^{\star \star \star}$ \\
\hline
\end{tabular}

${ }^{1}$ For all dimensions higher scores correspond to better categorization efforts.

${ }^{2}$ Test performed: T-test for 2 related samples, t scores are reported

${ }^{3}$ Significance levels indicated as ${ }^{* *}$ for $\alpha<=0.01$. ${ }^{* *}$ for $\alpha<=0.05$ and * for $\alpha<=0.1$ 
Table 2a. Results of categorization analysis: number of cases clustered (HLIS1)

\begin{tabular}{|c|c|c|c|c|c|c|c|c|c|c|c|c|c|c|c|}
\hline & \multicolumn{3}{|c|}{$\begin{array}{c}\text { Category } 1 \\
\text { Cost allocation }\end{array}$} & \multicolumn{3}{|c|}{$\begin{array}{c}\text { Category } 2 \\
\text { Obligo entries }\end{array}$} & \multicolumn{3}{|c|}{$\begin{array}{c}\text { Category } 3 \\
\text { Valuation of assets }\end{array}$} & \multicolumn{3}{|c|}{$\begin{array}{c}\text { Category } 4 \\
\text { Consolidation }\end{array}$} & \multicolumn{3}{|c|}{ Categorization - total } \\
\hline Sample & Pre & Post & Test $^{2,3}$ & Pre & Post & Test $^{2,3}$ & Pre & Post & Test $^{2,3}$ & Pre & Post & Test $^{2,3}$ & Pre & Post & Test $^{2,3}$ \\
\hline Ecs-Low & 4.62 & 6.62 & $2.207^{*}$ & 5.12 & 6.37 & $2.017^{*}$ & 4.87 & 5.37 & 1.080 & 4.75 & 5.12 & 0.600 & 19.37 & 23.50 & $2.270^{*}$ \\
\hline Ecs-Med & 3.83 & 6.33 & $2.880^{* *}$ & 4.00 & 5.33 & $2.184^{* *}$ & 4.22 & 5.66 & $2.929^{\star \star *}$ & 3.77 & 5.11 & $1.879^{* *}$ & 15.83 & 22.33 & $2.869^{\star *}$ \\
\hline Ecs-High & 4.58 & 7.25 & $3.330^{\star * *}$ & 4.33 & 5.75 & $3.137^{* * *}$ & 5.08 & 5.50 & 0.594 & 4.91 & 5.91 & $2.708^{\star *}$ & 18.83 & 24.16 & $2.621^{* *}$ \\
\hline Ecs-Total & 4.23 & 6.68 & $4.814^{* \star *}$ & 4.34 & 5.68 & $3.947^{\star \star *}$ & 4.63 & 5.55 & $2.724^{* \star \star}$ & 4.34 & 5.36 & $2.728^{\star \star \star}$ & 17.52 & 23.15 & $4.370^{\star \star *}$ \\
\hline $\begin{array}{l}\text { Repeat } \\
\text { students }\end{array}$ & 5.13 & 6.00 & 1.373 & 4.73 & 5.66 & $2.114^{*}$ & 5.20 & 5.66 & 0.788 & 4.93 & 5.66 & 1.196 & 20.06 & 23.26 & 1.664 \\
\hline $\begin{array}{l}\text { Total } \\
\text { sample }\end{array}$ & 4.43 & 6.40 & $4.865^{\star \star \star}$ & 4.40 & 5.61 & $4.610^{* * *}$ & 4.74 & 5.52 & $2.765^{\star * *}$ & 4.41 & 5.40 & $3.181^{\star \star *}$ & 17.98 & 22.80 & $4.707^{\star \star *}$ \\
\hline
\end{tabular}

${ }^{1}$ For all dimensions higher scores correspond to better categorization efforts.

${ }^{2}$ Test performed: T-test for 2 related samples, $t$ scores are reported

${ }^{3}$ Significance levels indicated as ${ }^{* *}$ for $\alpha<=0.01$. ${ }^{* *}$ for $\alpha<=0.05$ and ${ }^{*}$ for $\alpha<=0.1$ 
Table 2b. Results of categorization analysis: number of topics recognised (HLIS2)

\begin{tabular}{|c|c|c|c|c|c|c|c|c|c|c|c|c|c|c|c|}
\hline & \multicolumn{3}{|c|}{$\begin{array}{c}\text { Category } 1 \\
\text { Cost allocation }\end{array}$} & \multicolumn{3}{|c|}{$\begin{array}{c}\text { Category } 2 \\
\text { Obligo entries }\end{array}$} & \multicolumn{3}{|c|}{$\begin{array}{c}\text { Category } 3 \\
\text { Valuation of assets }\end{array}$} & \multicolumn{3}{|c|}{$\begin{array}{c}\text { Category } 4 \\
\text { Consolidation }\end{array}$} & \multicolumn{3}{|c|}{ Categorization - total } \\
\hline Sample & Pre & Post & Test $^{2,3}$ & Pre & Post & Test $^{2,3}$ & Pre & Post & Test ${ }^{2,3}$ & Pre & Post & Test ${ }^{2,3}$ & Pre & Post & Test $^{2,3}$ \\
\hline Ecs-Low & 2.87 & 5.25 & 5.656 & 3.00 & 4.75 & 3.862 & 3.25 & 4.37 & $2.826^{\star \star}$ & 2.62 & 3.75 & 1.843 & 11.75 & 18.12 & $4.394^{\star \star \star}$ \\
\hline Ecs-Med & 2.94 & 5.22 & 4.644 & 2.94 & 4.38 & 4.738 & 3.44 & 4.05 & $2.170^{\star \star}$ & 2.33 & 4.05 & $3.791^{* \star \star}$ & 11.66 & 17.72 & $4.892^{\star \star \star}$ \\
\hline Ecs-High & 3.91 & 6.08 & $3.170^{* \star \star}$ & 3.58 & 5.08 & $3.761^{\star \star \star}$ & 4.08 & 4.58 & $1.254^{\star *}$ & 2.91 & 4.75 & $3.363^{\star \star \star}$ & 14.00 & 20.50 & $3.818^{\star \star \star}$ \\
\hline Ecs-Total & 3.23 & 5.50 & $7.038^{* * *}$ & 3.15 & 4.68 & $7.299^{* * *}$ & 3.60 & 4.28 & $3.422^{* * *}$ & 2.57 & 4.21 & $5.520^{* * *}$ & 12.57 & 18.68 & $7.574^{* \star *}$ \\
\hline $\begin{array}{l}\text { Repeat } \\
\text { students }\end{array}$ & 4.33 & 4.66 & 0.791 & 4.06 & 4.26 & 0.642 & 4.26 & 4.20 & 0.269 & 3.20 & 3.66 & 0.722 & 15.86 & 16.80 & 0.695 \\
\hline $\begin{array}{l}\text { Total } \\
\text { sample }\end{array}$ & 3.54 & 5.41 & $5.458^{\star \star \star}$ & 3.38 & 4.49 & $5.946^{\star \star \star}$ & 3.76 & 4.20 & $2.634^{\star *}$ & 2.70 & 3.98 & $4.605^{\star \star \star}$ & 13.40 & 17.81 & $5.914^{\star \star \star}$ \\
\hline
\end{tabular}

${ }^{1}$ For all dimensions higher scores correspond to better categorization efforts. Category scores may range from 0 to 8 , while to overall categorization score may range from 0 to 32 .

${ }^{2}$ Test performed: T-test for 2 related samples, $t$ scores are reported

${ }^{3}$ Significance levels indicated as ${ }^{* *}$ for $\alpha<=0.01$. ${ }^{* *}$ for $\alpha<=0.05$ and ${ }^{*}$ for $\alpha<=0.1$ 
Table 2c. Results of categorization analysis: number of correct classifications (HLIS3)

\begin{tabular}{|c|c|c|c|c|c|c|c|c|c|c|c|c|c|c|c|}
\hline & \multicolumn{3}{|c|}{$\begin{array}{c}\text { Category } 1 \\
\text { Cost allocation }\end{array}$} & \multicolumn{3}{|c|}{$\begin{array}{c}\text { Category } 2 \\
\text { Obligo entries }\end{array}$} & \multicolumn{3}{|c|}{$\begin{array}{c}\text { Category } 3 \\
\text { Valuation of assets }\end{array}$} & \multicolumn{3}{|c|}{$\begin{array}{c}\text { Category } 4 \\
\text { Consolidation }\end{array}$} & \multicolumn{3}{|c|}{ Categorization - total } \\
\hline Sample & Pre & Post & Test $^{2,3}$ & Pre & Post & Test $^{2,3}$ & Pre & Post & Test $^{2,3}$ & Pre & Post & Test ${ }^{2,3}$ & Pre & Post & Test $^{2,3}$ \\
\hline Ecs-Low & 1.62 & 1.50 & 0.424 & 0.37 & 1.12 & $2.393^{* *}$ & 0.50 & 0.50 & 0.000 & 0.50 & 1.50 & $2.646^{\star *}$ & 3.00 & 4.26 & $2.303^{*}$ \\
\hline Ecs-Med & 1.50 & 1.88 & 1.441 & 0.22 & 1.22 & 4.675 & 0.50 & 0.33 & 0.546 & 1.05 & 2.77 & $4.787^{* \star \star}$ & 3.27 & 6.22 & $5.127^{* * \star}$ \\
\hline Ecs-High & 2.00 & 1.58 & 0.834 & 0.16 & 2.00 & $5.698^{\star \star \star}$ & 0.41 & 0.66 & 1.149 & 1.58 & 2.50 & $2.688^{* *}$ & 4.16 & 6.75 & $2.745^{\star \star}$ \\
\hline Ecs-Total & 1.68 & 1.71 & 0.122 & 0.23 & 1.44 & $7.149^{* * *}$ & 0.47 & 0.47 & 0.000 & 1.10 & 2.42 & $5.138^{* \star *}$ & 3.50 & 6.05 & $5.989^{* * *}$ \\
\hline $\begin{array}{l}\text { Repeat } \\
\text { students }\end{array}$ & 1.53 & 1.26 & 1.169 & 0.60 & 1.20 & $2.358^{\star \star}$ & 0.66 & 0.53 & 0.487 & 1.40 & 2.13 & 1.434 & 4.20 & 5.13 & 1.191 \\
\hline $\begin{array}{l}\text { Total } \\
\text { sample }\end{array}$ & 1.70 & 1.58 & 0.734 & 0.28 & 1.10 & $6.642^{\star \star \star}$ & 0.48 & 0.48 & 0.000 & 1.18 & 2.07 & $4.341^{\star \star \star}$ & 3.65 & 5.24 & $4.774^{\star \star \star}$ \\
\hline
\end{tabular}

${ }^{1}$ For all dimensions higher scores correspond to better categorization efforts. Category scores may range from 0 to 4 , while to overall categorization score may range from 0 to 16 .

${ }^{2}$ Test performed: T-test for 2 related samples, $t$ scores are reported

${ }^{3}$ Significance levels indicated as ${ }^{* *}$ for $\alpha<=0.01$. ${ }^{* *}$ for $\alpha<=0.05$ and ${ }^{*}$ for $\alpha<=0.1$ 
